Article

\title{
Serum Paraoxonase-1 Activity and the Risk of Prostate Cancer Recurrence in Patients Treated with Radiotherapy
}

\author{
Milosz Jasinski ${ }^{1, *(D)}$ and Dorota Olszewska-Slonina ${ }^{2}$ (D) \\ 1 Department of Urology, Institute of Oncology, Romanowskiej 2, 85-796 Bydgoszcz, Poland \\ 2 Department of Pathobiochemistry and Clinical Chemistry, Collegium Medicum of Nicolaus Copernicus \\ University, M. Curie-Skłodowskiej 9, 85-094 Bydgoszcz, Poland; dorolsze@cm.umk.pl \\ * Correspondence: miloszj@onet.pl
}

Citation: Jasinski, M.;

Olszewska-Slonina, D. Serum

Paraoxonase-1 Activity and the Risk

of Prostate Cancer Recurrence in

Patients Treated with Radiotherapy.

Antioxidants 2022, 11, 346. https://

doi.org/10.3390/antiox11020346

Academic Editors: Monica Emanuelli and Roberto Campagna

Received: 30 December 2021

Accepted: 8 February 2022

Published: 10 February 2022

Publisher's Note: MDPI stays neutral with regard to jurisdictional claims in published maps and institutional affiliations.

Copyright: (C) 2022 by the authors. Licensee MDPI, Basel, Switzerland. This article is an open access article distributed under the terms and conditions of the Creative Commons Attribution (CC BY) license (https:// creativecommons.org/licenses/by/ $4.0 /)$.

\begin{abstract}
The antioxidant paraoxonase-1 (PON1) may be involved in the response to radiationinduced oxidative stress and possibly prevent cell apoptosis. The correlation of PON1 with the risk of cancer recurrence after radiotherapy (RT) is not yet explored. We investigated changes in the activity of PON1 in patients with prostate cancer (PCa) undergoing RT, and the relation of PON1 activity to the risk of recurrence after RT. We included 56 men with PCa. Blood samples were obtained before irradiation and after the completion of RT. Patients were followed for an average of 51.2 months. Each case of biochemical recurrence was confirmed with biopsy. The control group was composed of 60 healthy men. There was no significant difference in PON1 activity between the control group and patients pre-radiotherapy. Irradiation was associated with a significant decrease in PON1 activity. Patients with PCa recurrence had significantly higher serum PON1 activity than those recurrence-free, both before and after RT. PON1 activity was a predictor of PCa recurrence, with sensitivity over $80 \%$ and specificity over $64 \%$. Our results suggest that PON1 activity may be a predictor of PCa recurrence risk after RT. Studies with a larger number of patients and longer follow-up are needed to confirm this hypothesis.
\end{abstract}

Keywords: paraoxonase-1; prostate cancer; radiotherapy; recurrence

\section{Introduction}

Prostate cancer (PCa) is one of the most common forms of cancer in men worldwide, with radiotherapy (RT) being one of the main modalities used to treat it at the present time [1]. PCa cells, however, may develop resistance to radiation. This highly unpredictable mechanism renders the treatment less effective and frequently causes recurrence after radical RT-up to one-third of PCa patients experience biochemical failure after RT [2]. Despite identifying several molecular mechanisms associated with radioresistance, the ability to predict an individual PCa patient's response to RT is still limited and based mostly on the pretreatment assessment of prostate specific antigen (PSA), tumor stage and Gleason score $[3,4]$. Therefore, there is a need to identify new biomarkers that could more accurately predict response to $\mathrm{RT}$.

The majority of radiation-induced cell damage is caused by the indirect effect of free radicals produced in the effect of water radiolysis. These free radicals can initiate a chain of reactions that results in biological damage and further induces reactive oxygen species (ROS) [3,5]. PCa cells have a higher level of ROS compared with normal prostate cells and maintaining a balance of ROS levels in cancer is an important mechanism of radioresistance; RT also induces antioxidant defense systems, which may lead to radioresistance [6-9]. All these reasons justify the interest in the antioxidative mechanisms in the response of cancer cells to radiation-induced damage.

Paraoxonase-1 (PON1) is an antioxidant enzyme expressed in a variety of tissues but synthesized primarily in the liver. A portion is secreted into the plasma, where it is 
associated with high-density lipoproteins [10,11]. Oxidative stress and lipid peroxidation products play a role in oncogenesis, which may suggest that PON1 is associated with cancer [12]. There is a large inter-individual variability in serum PON1 activity, which can be partially attributed to the polymorphisms of the PON1 gene. Reduced PON1 activities have been reported in different groups of patients, including those with diabetes mellitus, cardiovascular disease and hypercholesterolemia. Furthermore, a number of epidemiological studies have investigated the associations between these polymorphisms and different malignancies, such as lung, breast, brain, ovarian and prostate cancers [11,13].

PON1, due to its antioxidative function, may be involved in response to radiationinduced damage and prevent radiation-induced cell apoptosis. The possible correlation of serum PON1 activity with the risk of cancer recurrence after RT is not yet fully explored, with few such studies described in the literature and none about PCa [11,14,15].

The aim of this study was to investigate the relation between serum PON1 activity and the relapse of prostate cancer in patients undergoing RT.

\section{Materials and Methods}

Fifty-six men (mean age $68.17 \pm 6.95$ years, range 53-80) undergoing RT for prostate cancer in the years 2005-2010 in the Department of Brachytherapy of the Institute of Oncology in Bydgoszcz, Poland were included in the prospective study. All patients had biopsy-proven prostate cancer (clinical stage T1-T3bN0M0). The average PSA before treatment was $13.35 \mathrm{ng} / \mathrm{mL}$. All patients had pelvic magnetic resonance imaging before treatment, and prostate volume was measured in magnetic resonance images. Thirtyone patients received hormone therapy together with radiation treatment. The radiation schedule was external beam RT 46 Gy (Grey) in 23 fractions (2 Gy/day) combined with two 10 Gy high-dose-rate brachytherapy fractions [16].

Blood samples were obtained prior to irradiation and after completion of irradiation 7-8 weeks later. Sera were stored at $-80{ }^{\circ} \mathrm{C}$ until biochemical analysis, however, not for more than two months. Serum PON1 activity was determined according to Playfer et al., modified by Sogorb et al., as the rate of hydrolysis of paraoxon at $37^{\circ} \mathrm{C}$, in a TRIS/ $\mathrm{HCl}$ buffer (2-Amino-2-(hydroxymethyl)propane-1,3-diol/ $\mathrm{HCl}$ buffer), $\mathrm{pH}$ 10.5, with $\mathrm{CaCl}_{2}$; activities were expressed as IU/L [17,18].

Patients were followed by PSA measurement every 3 months during the first 2 years, then every 6 months until 5 years and annually after 5 years. Biochemical recurrence was defined according to RTOG-ASTRO Phoenix criteria [19]. In every case, PCa recurrence was confirmed by prostate biopsy. The schematic design of the study is presented in Figure 1. The control group consisted of 60 healthy men (mean age $63.0 \pm 13.2$ years, range 56-74). They had no clinical evidence of prostate cancer nor any other malignancy.

The study was conducted in accordance with the Declaration of Helsinki. All participants (study and control group) signed written consent, provided that the anonymity of the data was guaranteed. The study was approved by the local Ethics Committee (KB/424/2005 with an annex).

Differences between any two independent groups were assessed using a Student's $t$-test or Mann-Whitney U-test. The Wilcoxon signed-rank test was used for comparisons of dependent variables. The $\chi$-square test was employed to evaluate differences in qualitative variables. The diagnostic accuracy of measured variables was assessed by the receiver operating characteristics (ROC) curve. The area under the curve (AUC) and 95\% confidence interval values were also determined. $p<0.05$ was considered statistically significant. 


\section{PCa patients}

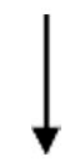

PON1 activity before RT (56 patients)

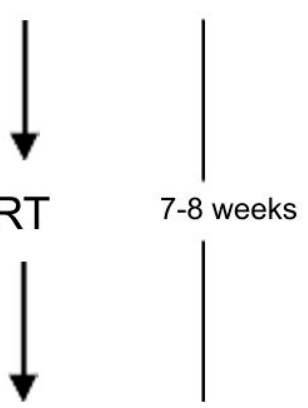

\section{PON1 activity after RT (46 patients)}

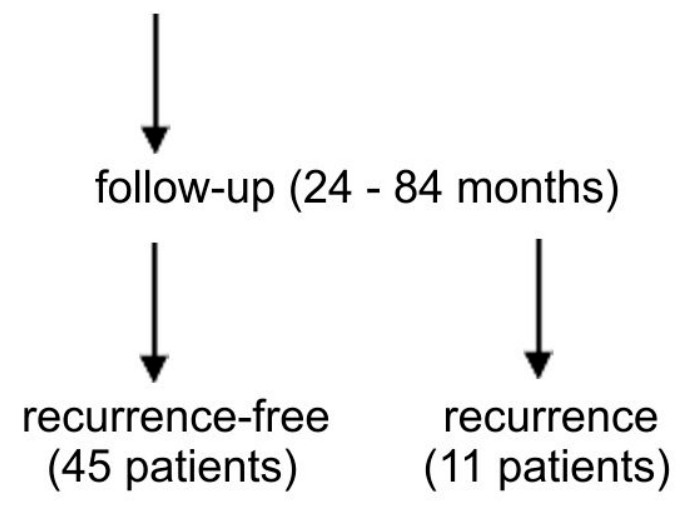

Figure 1. The schematic design of the study. PCa-prostate cancer, PON1-paraoxonase-1, RT-radiotherapy.

\section{Results}

\subsection{Clinical Characteristics of PCa Patients}

During the follow-up period, in 11 patients, biopsy-confirmed recurrence was diagnosed (group 1), and 45 remained recurrence-free (group 2). The main clinical characteristics of patients with and without biochemical recurrence are presented in Table 1. No significant differences were observed in age, prostate volume nor the percent of patients receiving hormonal therapy were found between the groups. Regarding TNM classification, most of the patients were classified as $\mathrm{T} 1$ or $\mathrm{T} 2$, Gleason $<7$. There were no $\mathrm{N}+$ or $\mathrm{M}+$ patients in the classification before treatment. There were no significant differences between the groups in the risk group, according to d'Amico et al. [20].

The average follow-up length was 51.2 months (24-84). In four cases from the recurrence-free group, the follow-up time was less than 36 months; in the rest of the patients, it was at least 36 months. 
Table 1. Clinical and demographic characteristics of prostate cancer patients.

\begin{tabular}{|c|c|c|c|}
\hline $\begin{array}{l}\text { Clinical and Demographic } \\
\text { Characteristics }\end{array}$ & PCa Recurrence & PCa Recurrence-Free & $p$-Value \\
\hline$n$ & 11 & 45 & \\
\hline Age (mean \pm SD) $[y]$ & $68.09 \pm 6.16$ & $68.20 \pm 7.20$ & $p=0.96 *$ \\
\hline TNM & & & $p=0.26$ \\
\hline $\mathrm{T} 1$ & $9.1 \%(n=1)$ & $24.4 \%(n=11)$ & \\
\hline $\mathrm{T} 2$ & $81.8 \%(n=9)$ & $66.7 \%(n=30)$ & \\
\hline T3 & $9.1 \%(n=1)$ & $8.9 \%(n=4)$ & \\
\hline Gleason score & & & $p=0.42$ \\
\hline$<7$ & $63.6 \%(n=7)$ & $75.6 \%(n=34)$ & \\
\hline 7 & $18.2 \%(n=2)$ & $13.3 \%(n=6)$ & \\
\hline$>7$ & $18.2 \%(n=2)$ & $11.1 \%(n=5)$ & \\
\hline $\mathrm{PSA}($ mean $\pm \mathrm{SD}$ ) $[\mathrm{ng} / \mathrm{mL}]$ & $19.7 \pm 26.16$ & $11.8 \pm 8.35$ & $p=0.85 *$ \\
\hline Risk group & & & $p=0.82$ \\
\hline Low & $36.4 \%(n=4)$ & $33.3 \%(n=15)$ & \\
\hline Intermediate & $36.4 \%(n=4)$ & $44.4 \%(n=20)$ & \\
\hline High & $27.2 \%(n=3)$ & $22.3 \%(n=10)$ & \\
\hline Prostate volume (mean \pm SD) $[\mathrm{mL}]$ & $37.9 \pm 15.1$ & $33.2 \pm 14.3$ & $p=0.37^{* *}$ \\
\hline Hormone therapy & $45 \%(n=5)$ & $58 \%(n=26)$ & $p=0.46$ \\
\hline
\end{tabular}

PCa-prostate cancer, $y$-year. Statistical analyses were performed by the $\chi$-square test; ${ }^{*}$ Student's $t$-test; ${ }^{* *}$ MannWhitney U test.

\subsection{Alterations in PON1 Activity}

PON1 activity in the control group was $83.9 \pm 34.5 \mathrm{IU} / \mathrm{L}(n=60$, median $76.0 \mathrm{IU} / \mathrm{L}$ 24.3-200.6 IU/L) while in the PCa group pre-radiotherapy was $81.3 \pm 41.6 \mathrm{IU} / \mathrm{L}(n=56$, median $76.1 \mathrm{IU} / \mathrm{L}, 20.0-169.9 \mathrm{IU} / \mathrm{L})$. There was no significant difference in PON1 activity between the control group and PCa patients pre-radiotherapy $(p=0.582)$.

In 10 patients (two from the recurrence group and eight from the recurrence-free group), PON1 activity was measured only before radiotherapy. RT was associated with a significant decrease in PON1 activity $(p=0.01)$ (Table 2).

Table 2. Serum paraoxonase-1 (PON1) activity in prostate cancer patients before and after radiotherapy (RT).

\begin{tabular}{cccc}
\hline $\boldsymbol{n}=\mathbf{4 6}$ & PON1 before RT [IU/L] & PON1 after RT [IU/L] & Wilcoxon Test \\
\cline { 1 - 3 } Mean \pm SD & $83.5 \pm 43.2$ & $74.5 \pm 55.0$ & \\
\cline { 1 - 3 } Median (range) & $75.0(20.0-169.9)$ & $55.6(11.2-236.8)$ & \\
\hline
\end{tabular}

A decrease in PON1 activity (activity after RT lower than the one before RT) was observed in 33 of 46 cases.

\subsection{Relationship between PON1 Activity and the PCa Recurrence}

When comparing patients who remained recurrence-free to those with PCa recurrence diagnosed during follow-up, there was a significant difference in PON1 activity.

Serum PON1 activities were higher in the recurrence group, and these differences were significant both before and after radiotherapy (Table 3). 
Table 3. Serum paraoxonase-1 (PON1) activity before and after radiotherapy in prostate cancer patients who experienced recurrence after treatment and in patients who remained recurrence-free.

\begin{tabular}{|c|c|c|c|}
\hline Serum PON1 Activity & Recurrence & Recurrence-Free & Mann-Whitney Test \\
\hline$n$ & 11 & 45 & \\
\hline $\begin{array}{c}\text { PON1 before RT [IU /L] } \\
\text { mean } \pm \text { SD }\end{array}$ & $111.3 \pm 40.7$ & $74.0 \pm 38.9$ & \multirow[t]{2}{*}{$p=0.012$} \\
\hline Median (range) & $118.4(27.8-158.0)$ & $69.2(20.0-169.9)$ & \\
\hline$n$ & 9 & 37 & \\
\hline $\begin{array}{c}\text { PON1 after RT [IU /L] } \\
\text { mean } \pm \text { SD }\end{array}$ & $106.4 \pm 44.2$ & $66.7 \pm 53.8$ & \multirow[t]{2}{*}{$p=0.017$} \\
\hline Median (range) & $112.4(37.9-186.1)$ & $40.3(11.2-236.8)$ & \\
\hline
\end{tabular}

The statistical analysis identified PON1 as the parameter that discriminated between PCa recurrence group and recurrence-free group. ROC analysis of this parameter showed that PON1 activity allowed identification of patients in whom biochemical recurrence of PCa was later diagnosed with an AUC value of 0.746 (sensitivity $81.8 \%$, specificity $64.4 \%$ ) for the value before RT and AUC value of 0.757 (sensitivity $88.9 \%$, specificity $64.9 \%$ ) for the value after RT (Figure 2). RT-radiotherapy, SD-standard deviation
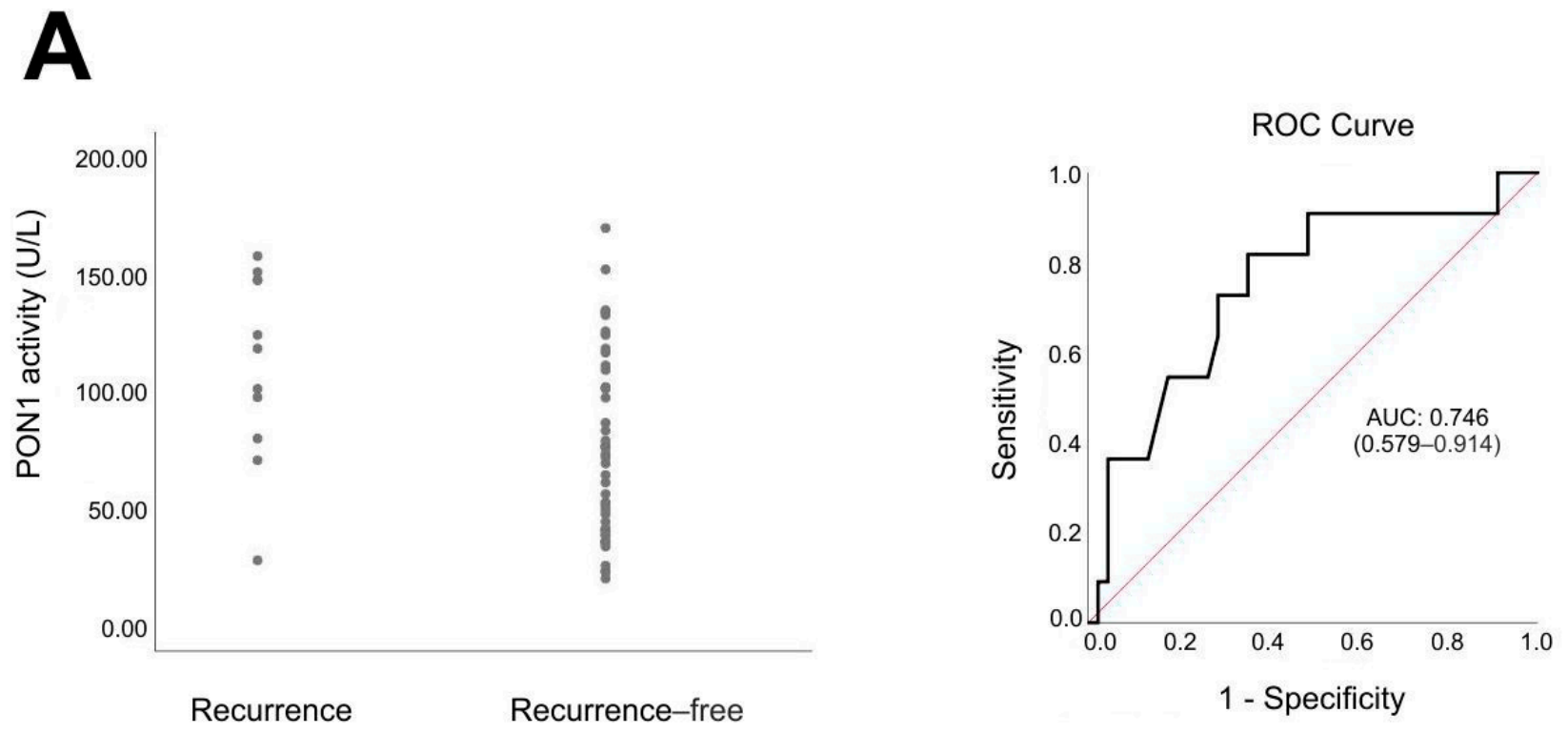

Sensitivity \%

Specificity \% 81.8 64.4

Figure 2. Cont. 


\section{B}
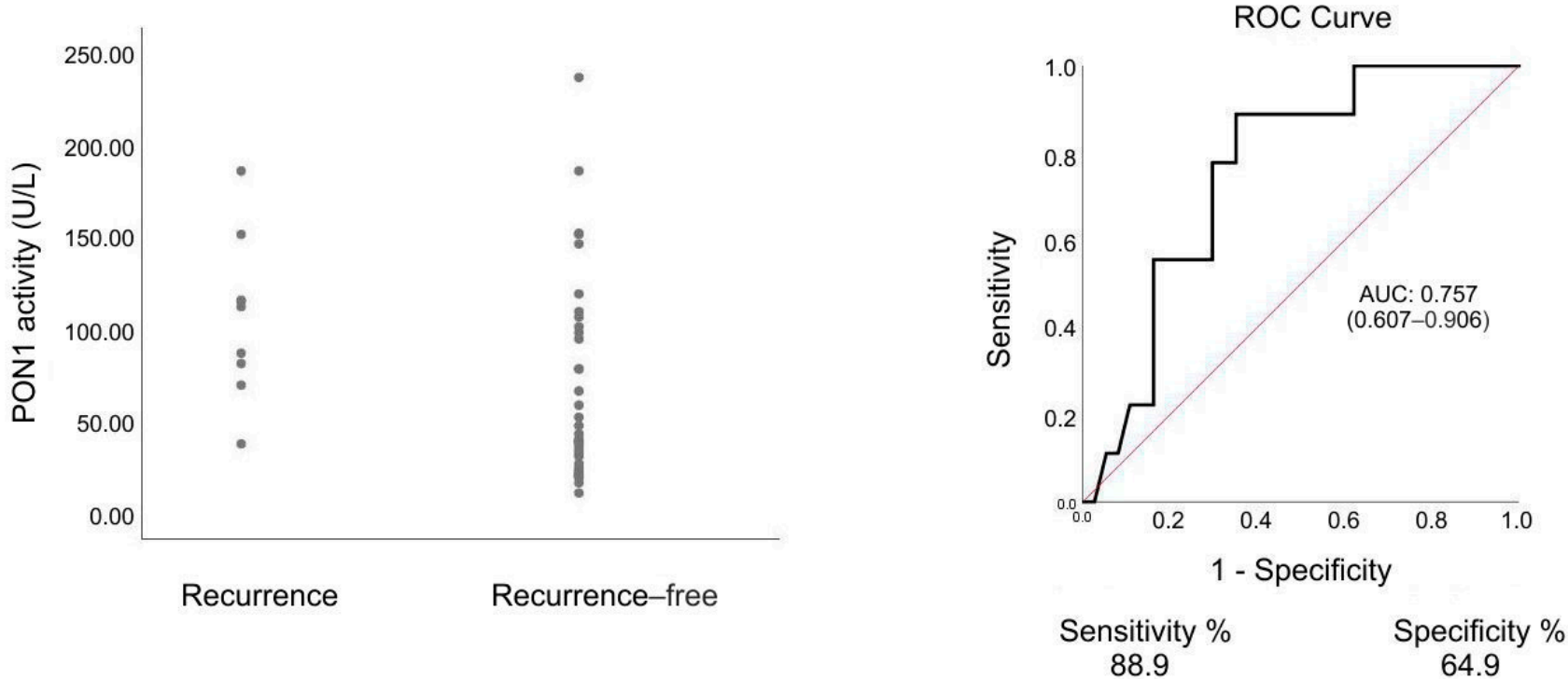

Figure 2. Serum paraoxonase-1 (PON1) activity and receiver operating characteristic (ROC) curves in patients with prostate cancer. (A) before radiotherapy, recurrence group vs. recurrence-free group, $p=0.012$, Mann-Whitney U test. (B) After radiotherapy, recurrence group vs. recurrence-free group, $p=0.017$, Mann-Whitney U test.

\section{Discussion}

PON1 is one of a family of three enzymes, called PON1, PON2 and PON3, which degrade lipid peroxides in circulating lipoproteins and in the cytoplasmic and intracellular organelle membranes of cells [21]. These enzymes are linked to mitochondria-associated membranes, which modulate mitochondrial metabolism and prevent apoptosis. There are variations of serum PON1 activity in the population. One source of the variability is the polymorphism in the coding and in the promoter region of the PON1 gene. There are also exogenous factors modulating PON1 activity and levels of expression, such as certain drugs, dietary factors, and lifestyle factors. Costa et al., in their review, described several factors responsible for the differences in PON1 activity in populations [22]. There are numerous studies linking PON1 with the risk of cancer, including PCa [12,13,23-25]. Several studies have also reported decreased serum PON1 activity in cancer patients [14]. While Bedir et al. observed lower levels of PON1 in patients diagnosed with $\mathrm{PCa}$, but before treatment, than in healthy population, the exact mechanism involved in the decrease in PON1 activity in PCa patients is still unclear [26]. In our study, we did not observe such a difference between PCa patients before treatment and the control group. We did, however, find a significant decrease in PON1 activity after RT. This phenomenon is not surprising - RT leads to elevated oxidative stress and degrades lipid peroxides, PON1 binds covalently to lipid molecules leading to enzyme inactivation [27]. Hence, the result of increased oxidative stress is decreased PON1 activity. A similar decrease in serum PON1 activity after RT has also been observed in other studies [14,15].

The most noteworthy result of this study is the significant difference in PON1 activity between the group of patients who were diagnosed with PCa recurrence and those who remained recurrence-free. As far as we know, this is the first study to investigate associations of the PON1 activity with the response to RT in PCa patients. Interestingly, PON1 activity, both before and after RT, was the only statistically significant difference between recurrence and recurrence-free groups in this study. The AUC of the ROC curves of PON1 activity in the distinction between patients with and without PCa recurrence after RT were 0.746 and 0.757 , which are favorable in comparison with prediction models based on clinical 
variables and imaging features [28]. Our study suggests that the determination of PON1 activity may be a potential marker in the prediction of PCa response to RT. If an $80 \mathrm{U} / \mathrm{L}$ cut-off value of PON1 activity before RT was used, it could predict PCa recurrence in the studied group with almost $82 \%$ sensitivity and over $64 \%$ specificity. Rodriguez-Tomas et al., in their study on lung cancer, made a somewhat similar observation-patients who presented a complete response after RT had lower PON1 serum concentrations than those who presented a partial response or did not respond to RT [14]. While we did not measure the PON1 serum concentration in our study, it could be worth investigating if there is such a relation in PCa patients.

Available literature provides no explanation of the reasons for this observation, nor can they be deduced from the present study. We may, however, suggest two possible mechanisms based on the role of PON1 and the metabolic changes induced by the cancerrelated increased oxidative stress, which are not mutually exclusive.

First, the antioxidative role of PON1 may partially protect PCa cells from radiationinduced damage, and this protective effect may be stronger in patients with higher serum PON1 concentration and activity. One of the mechanisms of radiation-induced cell damage involves damage of mitochondrial integrity, leading to mitochondrial dysfunction, increased oxidative stress and cell death. Radiation increases mitochondrial ROS production by inducing secondary ROS generation via electron leakage from the mitochondrial electron transport chain complexes [29-31]. On the other hand, overexpression of the enzymes from the PON family prevents mitochondrial dysfunction-they are linked to mitochondrial membranes, modulate mitochondrial metabolism and prevent apoptosis [32-34]. It is also suspected that cancer cells can scavenge serum PON1 and take advantage of its antioxidative effects [35-37].

Second, a decrease in serum PON1 activity may be a marker of the radiosensitivity of PCa. The response of cells to radiation strongly depends on oxygen, with hypoxia reported as one of the mechanisms leading to radioresistance [38]. Milosevic et al. found that local hypoxia was associated with a higher risk of PCa recurrence after RT [39]. Hypoxia has a significant effect on cell metabolism-a low basal ROS level is maintained in hypoxic cells by reduced mitochondrial ROS production and promotion of ROS detoxification processes $[40,41]$. This may lead to a hypothesis that the mechanisms involved in hypoxiainduced radioresistance also lead to a decrease in cancer-related increased oxidative stress and thus partially prevent the decrease of serum PON1 activity.

What is also important, PON1 activity was higher in the recurrence group even before the treatment. Therefore, it may be a useful marker in clinical decision making. There is a large group of PCa patients with localized disease who may be treated either by radical prostatectomy or RT, without a clear indication for one of these modalities. Knowing who may be potentially at greater risk of PCa recurrence after RT could result in offering some of these patients the alternative treatment method (radical prostatectomy).

This study has several limitations. Due to the number of patients studied, the recurrence group is small. The length of follow-up may not be enough to observe every recurrence in the case of $\mathrm{PCa}$, and there is a risk that some late recurrences were omitted. Our results should be validated and confirmed in larger, preferably multi-center studies with longer follow-up. Further studies would also be essential to determine the cut-off value of PON1 activity, predicting the risk of PCa recurrence after RT and the possible relation of PON1 concentration with the risk of recurrence, especially since such relations were reported for lung and breast cancers [11,14]. This is the first study investigating PON1 activity in relation to the risk of PCa recurrence after radiotherapy; therefore, information available in the literature on this subject is scarce, limiting the quality of the discussion.

\section{Conclusions}

The results of the present study suggest the usefulness of investigating alterations in oxidative stress during RT in PCa patients. We conclude that PCa patients presented a significant decrease in serum PON1 activity during RT. Moreover, we observed significantly 
higher PON1 activity in patients who experienced PCa recurrence after RT. Due to the small number of patients studied, our results must be considered preliminary, but they suggest that the determination of PON1 activity might be a valuable tool for the prediction of PCa recurrence after RT, possibly more accurate than prediction models based on clinical variables. Further studies are necessary to evaluate the usefulness of PON1 activity in this clinical situation and to determine the cut-off values.

Author Contributions: Conceptualization, M.J. and D.O.-S.; methodology, M.J. and D.O.-S.; validation, M.J. and D.O.-S.; formal analysis, M.J. and D.O.-S.; investigation, M.J. and D.O.-S.; data curation, M.J. and D.O.-S.; writing—original draft preparation, M.J.; writing—review and editing, D.O.-S. All authors have read and agreed to the published version of the manuscript.

Funding: This research received no external funding.

Institutional Review Board Statement: The study was conducted according to the guidelines of the Declaration of Helsinki, and approved by the Ethics Committee of CM UMK, Bydgoszcz, Poland (KB/424/2005 with an annex).

Informed Consent Statement: Informed consent was obtained from all subjects involved in the study.

Data Availability Statement: Data generated or analyzed during this study are included in this article. More detailed data are not publicly available due to their containing information that could compromise the privacy of patients. Further inquiries can be directed to the corresponding author.

Conflicts of Interest: The authors declare no conflict of interest.

\section{References}

1. Cooperberg, M.R.; Chan, J.M. Epidemiology of prostate cancer. World J. Urol. 2017, 35, 849. [CrossRef] [PubMed]

2. Lewin, R.; Amit, U.; Laufer, M.; Berger, R.; Dotan, Z.; Domachevsky, L.; Davidson, T.; Portnoy, O.; Tsvang, L.; Ben-Ayun, M.; et al. Salvage re-irradiation using stereotactic body radiation therapy for locally recurrent prostate cancer: The impact of castration sensitivity on treatment outcomes. Radiat. Oncol. 2021, 16, 114. [CrossRef] [PubMed]

3. Chaiswing, L.; Weiss, H.L.; Jayswal, R.D.; Clair, D.K.S.; Kyprianou, N. Profiles of Radioresistance Mechanisms in Prostate Cancer. Crit. Rev. Oncog. 2018, 23, 39-67. [CrossRef]

4. Abdel-Messeih, P.L.; Nosseir, N.M.; Bakhe, O.H. Evaluation of inflammatory cytokines and oxidative stress markers in prostate cancer patients undergoing curative radiotherapy. Central Eur. J. Immunol. 2017, 42, 68-72. [CrossRef]

5. Miao, L.; Holley, A.K.; Zhao, Y.; Clair, W.H.S.; Clair, D.K.S. Redox-Mediated and Ionizing-Radiation-Induced Inflammatory Mediators in Prostate Cancer Development and Treatment. Antioxid. Redox Signal. 2014, 20, 1481-1500. [CrossRef]

6. Reuter, S.; Gupta, S.C.; Chaturvedi, M.M.; Aggarwal, B.B. Oxidative stress, inflammation, and cancer: How are they linked? Free Radic. Biol. Med. 2010, 49, 1603-1616. [CrossRef]

7. Qu, Y.; Zhang, H.; Zhao, S.; Hong, J.; Tang, C. The effect on radioresistance of manganese superoxide dismutase in nasopharyngeal carcinoma. Oncol. Rep. 2010, 23, 1005-1011. [CrossRef]

8. Riley, P.A. Free Radicals in Biology: Oxidative Stress and the Effects of Ionizing Radiation. Int. J. Radiat. Biol. 1994, 65, 27-33. [CrossRef]

9. Guo, G.; Yan-Sanders, Y.; Lyn-Cook, B.D.; Wang, T.; Tamae, D.; Ogi, J.; Khaletskiy, A.; Li, Z.; Weydert, C.; Longmate, J.; et al. Manganese Superoxide Dismutase-Mediated Gene Expression in Radiation-Induced Adaptive Responses. Mol. Cell. Biol. 2003, 23, 2362-2378. [CrossRef] [PubMed]

10. Précourt, L.-P.; Amre, D.; Denis, M.-C.; Lavoie, J.-C.; Delvin, E.; Seidman, E.; Levy, E. The three-gene paraoxonase family: Physiologic roles, actions and regulation. Atheroscler. 2011, 214, 20-36. [CrossRef]

11. Arenas, M.; García-Heredia, A.; Cabré, N.; Luciano-Mateo, F.; Hernández-Aguilera, A.; Sabater, S.; Bonet, M.; Gascón, M.; Fernández-Arroyo, S.; Fort, I.; et al. Effect of radiotherapy on activity and concentration of serum paraoxonase- 1 in breast cancer patients. PLoS ONE 2017, 12, e0188633. [CrossRef]

12. Elkiran, E.T.; Mar, N.; Aygen, B.; Gursu, F.; Karaoglu, A.; Koca, S. Serum paraoxonase and arylesterase activities in patients with lung cancer in a Turkish population. BMC Cancer 2007, 7, 48. [CrossRef]

13. Fang, D.-H.; Fan, C.-H.; Ji, Q.; Qi, B.-X.; Li, J.; Wang, L. Differential effects of paraoxonase 1 (PON1) polymorphisms on cancer risk: Evidence from 25 published studies. Mol. Biol. Rep. 2012, 39, 6801-6809. [CrossRef]

14. Rodríguez-Tomàs, E.; Murcia, M.; Arenas, M.; Arguis, M.; Gil, M.; Amigó, N.; Correig, X.; Torres, L.; Sabater, S.; Baiges-Gayà, G.; et al. Serum Paraoxonase-1-Related Variables and Lipoprotein Profile in Patients with Lung or Head and Neck Cancer: Effect of Radiotherapy. Antioxidants 2019, 8, 213. [CrossRef] 
15. Rodríguez-Tomàs, E.; Arenas, M.; Gómez, J.; Acosta, J.; Trilla, J.; López, Y.; Árquez, M.; Torres, L.; Araguas, P.; Hernández-Aguilera, A.; et al. Identification of potential metabolic biomarkers of rectal cancer and of the effect of neoadjuvant radiochemotherapy. PLoS ONE 2021, 16, e0250453. [CrossRef] [PubMed]

16. Woźniak, A.; Masiak, R.; Szpinda, M.; Mila-Kierzenkowska, C.; Woźniak, B.; Makarewicz, R.; Szpinda, A. Oxidative Stress Markers in Prostate Cancer Patients after HDR Brachytherapy Combined with External Beam Radiation. Oxid. Med. Cell. Longev. 2012, 2012, 789870. [CrossRef] [PubMed]

17. Playfer, J.R.; Eze, L.C.; Bullen, M.F.; Evans, D.A. Genetic polymorphism and interethnic variability of plasma paroxonase activity. J. Med Genet. 1976, 13, 337-342. [CrossRef] [PubMed]

18. Sogorb, M.A.; García-Argüelles, S.; Carrera, V.; Vilanova, E. Serum Albumin is as Efficient as Paraxonase in the Detoxication of Paraoxon at Toxicologically Relevant Concentrations. Chem. Res. Toxicol. 2008, 21, 1524-1529. [CrossRef] [PubMed]

19. Roach, M., 3rd; Hanks, G.; Thames, H., Jr.; Schellhammer, P.; Shipley, W.U.; Sokol, G.H.; Sandler, H. Defining biochemical failure following radiotherapy with or without hormonal therapy in men with clinically localized prostate cancer: Recommendations of the RTOG-ASTRO Phoenix Consensus Conference. Int. J. Radiat. Oncol. Biol. Phys. 2006, 65, 965-974. [CrossRef] [PubMed]

20. D'Amico, A.V.; Whittington, R.; Malkowicz, S.B.; Schultz, D.; Blank, K.; Broderick, G.A.; Tomaszewski, J.E.; Renshaw, A.A.; Kaplan, I.; Beard, C.J.; et al. Biochemical outcome after radical prostatectomy, external beam radiation therapy, or interstitial radiation therapy for clinically localized prostate cancer. JAMA 1998, 280, 969-974. [CrossRef]

21. Camps, J.; Marsillach, J.; Joven, J. The paraoxonases: Role in human diseases and methodological difficulties in measurement. Crit. Rev. Clin. Lab. Sci. 2009, 46, 83-106. [CrossRef] [PubMed]

22. Costa, L.G.; Vitalone, A.; Cole, T.B.; Furlong, C.E. Modulation of paraoxonase (PON1) activity. Biochem. Pharmacol. 2005, 69, 541-550. [CrossRef] [PubMed]

23. Antognelli, C.; Mearini, L.; Talesa, V.N.; Giannantoni, A.; Mearini, E. Association of CYP17, GSTP1, and PON1 polymorphisms with the risk of prostate cancer. Prostate 2005, 63, 240-251. [CrossRef] [PubMed]

24. Stevens, V.L.; Rodriguez, C.; Talbot, J.T.; Pavluck, A.L.; Thun, M.J.; Calle, E.E. Paraoxonase 1 (PON1) polymorphisms and prostate cancer in the CPS-II Nutrition Cohort. Prostate 2008, 68, 1336-1340. [CrossRef]

25. Samra, Z.Q.; Pervaiz, S.; Shaheen, S.; Dar, N.; Athar, M.A. Determination of oxygen derived free radicals producer (xanthine oxidase) and scavenger (paraoxonase1) enzymes and lipid parameters in different cancer patients. Clin. Lab. 2011, 57, $741-747$.

26. Bedir, F.; Kocatürk, H.; Altay, M.S.; Şebin, E.; Bedir, B. To examine serum paraoxonase 1 and 3 activities in benign and malignant diseases of the prostate, and changes in levels following robotic-assisted laparoscopic radical prostatectomy. Turk. J. Med Sci. 2020, 50, 1872-1878. [CrossRef]

27. Aviram, M.; Rosenblat, M.; Billecke, S.; Erogul, J.; Sorenson, R.; Bisgaier, C.L.; Newton, R.S.; La Du, B. Human serum paraoxonase (PON 1) is inactivated by oxidized low density lipoprotein and preserved by antioxidants. Free Radic. Biol. Med. 1999, 26, 892-904. [CrossRef]

28. Fernandes, C.D.; Dinh, C.V.; Walraven, I.; Heijmink, S.W.; Smolic, M.; van Griethuysen, J.J.; Simões, R.; Losnegård, A.; van der Poel, H.G.; Pos, F.J.; et al. Biochemical recurrence prediction after radiotherapy for prostate cancer with T2w magnetic resonance imaging radiomic features. Phys. Imaging Radiat. Oncol. 2018, 7, 9-15. [CrossRef]

29. Szumiel, I. Ionizing radiation-induced oxidative stress, epigenetic changes and genomic instability: The pivotal role of mitochondria. Int. J. Radiat. Biol. 2014, 91, 1-12. [CrossRef]

30. Brand, M.D. Mitochondrial generation of superoxide and hydrogen peroxide as the source of mitochondrial redox signaling. Free Radic. Biol. Med. 2016, 100, 14-31. [CrossRef]

31. Yamamori, T.; Yasui, H.; Yamazumi, M.; Wada, Y.; Nakamura, Y.; Nakamura, H.; Inanami, O. Ionizing radiation induces mitochondrial reactive oxygen species production accompanied by upregulation of mitochondrial electron transport chain function and mitochondrial content under control of the cell cycle checkpoint. Free Radic Biol Med. 2012, 53, 260-270. [CrossRef]

32. Camps, J.; García-Heredia, A.; Hernández-Aguilera, A.; Joven, J. Paraoxonases, mitochondrial dysfunction and non-communicable diseases. Chem. Interactions 2016, 259, 382-387. [CrossRef] [PubMed]

33. Li, X.; Zhang, K.; Li, Z. Unfolded protein response in cancer: The Physician's perspective. J. Hematol. Oncol. 2011, 4, 8. [CrossRef]

34. Grandi, A.; Santi, A.; Campagnoli, S.; Parri, M.; De Camilli, E.; Song, C.; Jin, B.; Lacombe, A.; Castori-Eppenberger, S.; Sarmientos, P.; et al. ERMP1, a novel potential oncogene involved in UPR and oxidative stress defense, is highly expressed in human cancer. Oncotarget 2016, 7, 63596-63610. [CrossRef] [PubMed]

35. Deakin, S.P.; Bioletto, S.; Bochaton-Piallat, M.-L.; James, R.W. HDL-associated paraoxonase-1 can redistribute to cell membranes and influence sensitivity to oxidative stress. Free Radic. Biol. Med. 2011, 50, 102-109. [CrossRef]

36. Aldonza, M.B.D.; Son, Y.S.; Sung, H.-J.; Ahn, J.M.; Choi, Y.-J.; Kim, Y.-I.; Cho, S.; Cho, J.-Y. Paraoxonase-1 (PON1) induces metastatic potential and apoptosis escape via its antioxidative function in lung cancer cells. Oncotarget 2017, 8, 42817-42835. [CrossRef] [PubMed]

37. Ahn, J.-M.; Sung, H.-J.; Yoon, Y.-H.; Kim, B.-G.; Yang, W.S.; Lee, C.; Park, H.-M.; Kim, B.-J.; Lee, S.-Y.; An, H.J.; et al. Integrated Glycoproteomics Demonstrates Fucosylated Serum Paraoxonase 1 Alterations in Small Cell Lung Cancer. Mol. Cell. Proteom. 2014, 13, 30-48. [CrossRef]

38. Bristow, R.G.; Hill, R.P. Hypoxia, DNA repair and genetic instability. Nat. Cancer 2008, 8, 180-192. [CrossRef] 
39. Milosevic, M.; Warde, P.; Menard, C.; Chung, P.; Toi, A.; Ishkanian, A.; McLean, M.; Pintilie, M.; Sykes, J.; Gospodarowicz, M.; et al. Tumor hypoxia predicts biochemical failure following radiotherapy for clinically localized prostate cancer. Clin. Cancer Res. 2012, 18, 2108-2114. [CrossRef] [PubMed]

40. Rakotomalala, A.; Escande, A.; Furlan, A.; Meignan, S.; Lartigau, E. Hypoxia in Solid Tumors: How Low Oxygenation Impacts the "Six Rs" of Radiotherapy. Front. Endocrinol. 2021, 12, 742215. [CrossRef]

41. Sgarbi, G.; Gorini, G.; Liuzzi, F.; Solaini, G.; Baracca, A. Hypoxia and IF1 Expression Promote ROS Decrease in Cancer Cells. Cells 2018, 7, 64. [CrossRef] [PubMed] 